\title{
Iridium(I)-Catalyzed Intramolecular Cycloisomerization of Enynes: Scope and Mechanistic Course
}

\author{
David F. Fernández, ${ }^{\dagger \S}$ Catarina A. B. Rodrigues,${ }^{\dagger \S}$ Martín Calvelo, ${ }^{\dagger}$ Moisés Gulías,${ }^{\dagger}$ José L. \\ Mascareñas, ${ }^{* \dagger}$ Fernando López ${ }^{* \dagger \dagger}$
}

${ }^{\dagger}$ Centro Singular de Investigación en Química Biolóxica e Materiais Moleculares (CiQUS), Departamento de Química Orgánica. Universidade de Santiago de Compostela, 15782 Santiago de Compostela, Spain.

‡Instituto de Química Orgánica General CSIC, Juan de la Cierva 3, 28006, Madrid, Spain

\begin{abstract}
We report an $\operatorname{Ir}(\mathrm{I})$-catalyzed cycloisomerization methodology that provides access to carbocyclic systems bearing exo-alkene moieties from alkynyl-equipped acyclic precursors. The method relies on the $\mathrm{C}-\mathrm{H}$ activation of olefinic and (hetero)aromatic $\mathrm{C}\left(\mathrm{sp}^{2}\right)-\mathrm{H}$ bonds, followed by an exo-cyclization to a tethered alkyne, and provides interesting cyclic diene products that are amenable of further elaboration. Importantly, DFT calculations suggests that, in contrast to related hydrocarbonations of alkenes in which either migratory insertions or $\mathrm{C}-\mathrm{C}$ reductive eliminations have been suggested to be rate determining, in our reactions, the energetic barrier of these steps is lower than that of the previous $\mathrm{C}-\mathrm{H}$ activation.
\end{abstract}

\section{KEYWORDS: Iridium, C-H activation, hydrocarbonation, catalysis, cyclization}

The development of methods for $\mathrm{C}-\mathrm{C}$ bond formation based on metal-promoted $\mathrm{C}-\mathrm{H}$ bond activations is revolutionizing modern synthetic chemistry. ${ }^{1}$ Of special interest are those methods that involve a metal catalyzed simple addition of $\mathrm{C}\left(\mathrm{sp}^{2}\right)-\mathrm{H}$ bonds across the $\mathrm{C}-\mathrm{C}$ unsaturated moiety of alkenes or alkynes, owing to their simplicity, constructive power, and full atom-economy. ${ }^{2}$ While the hydrocarbonation of alkenes present the interest of creating new stereocenters, the analog reactions with alkynes are of also great synthetic value as the alkenyl moiety of the product provides for further manipulations.

Most studies in this area have been focused on intermolecular processes, and on the use $\mathrm{Pd}, \mathrm{Ru}$ or $\mathrm{Rh}$ catalysts. ${ }^{1,2}$ In contrast, reports on iridium-promoted additions of $\mathrm{C}\left(\mathrm{sp}^{2}\right)-\mathrm{H}$ bonds across alkynes are very scarce, and essentially limited to precursors with (hetero)aromatic moieties. Noticeably, iridium promoted additions of alkenyl $\mathrm{C}-\mathrm{H}$ bonds to alkynes have not yet been described. ${ }^{3}$ More remarkable, regardless of the type of metal catalyst used, intramolecular additions to alkynes based on $\mathrm{C}-\mathrm{H}$ activation processes, are almost unknown. The only examples so far described consist of a $\mathrm{Rh}(\mathrm{I})$-catalyzed cyclization of $\alpha, \beta$-unsaturated imines containing tethered alkynes ${ }^{4}$ and a recent report on a $\operatorname{Ir}(\mathrm{I})$ or $\mathrm{Rh}(\mathrm{I})$-catalyzed $\mathrm{C}-\mathrm{H}$ alkenylation of indoles. ${ }^{5,6}$

From a mechanistic point of view, these hydrocarbonation processes catalyzed by low-valent transition metal complexes have been generally proposed to involve a $\mathrm{C}-\mathrm{H}$ oxidative addition step, followed by either an exo- or endo hydrometalation of the $\mathrm{C}-\mathrm{C}$ unsaturated bond. Finally, a $\mathrm{C}-\mathrm{C}$ reductive elimination would deliver the cyclic products (Scheme 1, eq 1. route a). However, recent mechanistic work suggested that a path based on a carbometalation/C-H reductive elimination sequence (route b, exo type), could better explain the Ircatalyzed hydrocarbonation of alkenes. ${ }^{7}$ Considering these intriguing mechanistic aspects, the scarce precedents on intramolecular hydroarylation and especially, hydroalkenylation of alkynes, ${ }^{4-6}$ and the constructive power of the cyclizations, we were prompted to investigate the performance of iridium catalysts in this type of reactions. ${ }^{8}$ Herein we report an $\operatorname{Ir}(\mathrm{I})$ catalyzed intramolecular addition of olefinic, aromatic and heteroaromatic precursors to tethered alkynes. These cycloisomerizations provide carbocyclic products containing an exoolefin, with complete stereoselectivity. The synthetic potential of the strategy is further stressed by coupling the cyclization process with a Diels-Alder cycloaddition in a single pot, which provides a direct and fully stereoselective entry to relatively complex polycarbocyclic systems bearing up to four stereocenters. Importantly, we provide DFT calculations that point to the $\mathrm{C}-\mathrm{H}$ activation as the step with higher activation barrier. This contrasts to the hydrocarbonation of alkenes, ${ }^{8}$ which has been proposed to proceed through a rate limiting carbometalation followed by $\mathrm{C}-\mathrm{H}$ reductive elimination. ${ }^{9}$

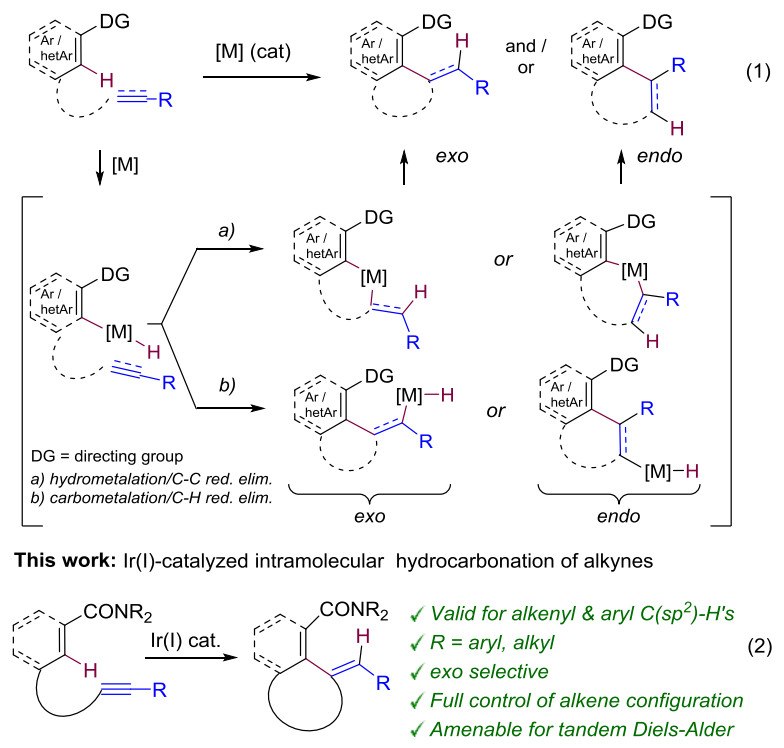

Scheme 1. Mechanistic scenario for metal-catalyzed hydrocarbonations (eq. 1, exo and endo), and our work (eq. 2). 
Considering the scarcity of intramolecular hydrocarbonations proceeding through the activation olefinic $\mathrm{C}\left(\mathrm{sp}^{2}\right)-\mathrm{H}$ bonds, ${ }^{10}$ we selected the alkenyl derivative 1a as model substrate. The complex $\left[\operatorname{Ir}(\operatorname{cod})_{2}\right] \mathrm{BArF} / \mathrm{d}^{\mathrm{F}} \mathrm{ppe}$, previously found successful for the hydrocarbonation of alkenes, ${ }^{8,11}$ was moderately efficient, providing the expected exo-cyclization product $\mathbf{2 a}$ in $61 \%$ yield $\left(24 \mathrm{~h}\right.$ heating at $100^{\circ} \mathrm{C}$ in 1,2 -DCE, Table 1 , entry 1). In addition to $\mathbf{2 a}$, traces of the trans isomer $\mathbf{2} \mathbf{a}$ ' $(<6 \%)$ could also be observed in the crude, whereas the endocyclization product (i.e. 4a) was not detected. Among bisphosphines, ${ }^{12}$ only BINAP improved this result $(70 \%$, entry 2 ), a value that could be improved up to $92 \%$ yield by using dioxane as solvent (entry 3). The use of monodentate phosphine ligands such as $\mathrm{Ph}_{3} \mathrm{P}$ proved unsuccessful (entry 4).

Table 1. Preliminary screening with $\mathbf{1 a}^{a}$

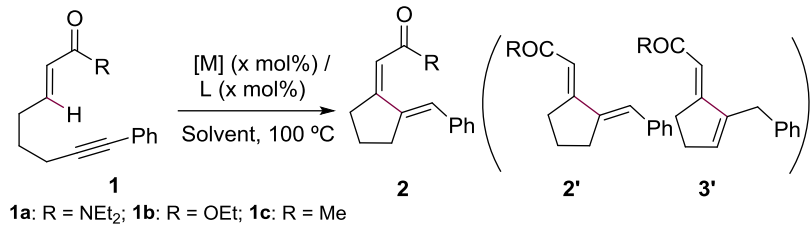

\begin{tabular}{|c|c|c|c|c|c|}
\hline atry & 1 & {$[\mathrm{M}](\mathrm{x} \mathrm{mol} \%)$} & Conv. & $\mathrm{L}$ & Prod \\
\hline $1^{c}$ & 1a & {$\left[\operatorname{Ir}(\operatorname{cod})_{2}\right] \mathrm{B} \operatorname{ArF}(5)$} & $77 \%$ & $\mathrm{~d}^{\mathrm{F}}$ ppe & 2a, $61 /$ \\
\hline $2^{c}$ & 1a & {$\left[\operatorname{Ir}(\operatorname{cod})_{2}\right] \mathrm{B} \operatorname{ArF}(5)$} & $80 \%$ & $r a c$-BINAP & $\mathbf{2 a}, 70 / \mathbf{2} \mathbf{a}^{\prime}, 2$ \\
\hline 3 & 1a & {$\left[\operatorname{Ir}(\operatorname{cod})_{2}\right] \mathrm{BArF}(5)$} & $99 \%$ & $r a c$-BINAP & $\mathbf{2 a}, 92$ / 2a', 4 \\
\hline $4^{d}$ & 1a & {$\left[\operatorname{Ir}(\operatorname{cod})_{2}\right] \mathrm{B} A r F(5)$} & $0 \%$ & $\mathrm{PPh}_{3}$ & - \\
\hline 5 & 1a & {$\left[\operatorname{Ir}(\operatorname{cod})_{2}\right] \mathrm{BF} 4(5)$} & $99 \%$ & $r a c$-BINAP 2 & $\mathbf{2 a}, 60$ / 2a', 3 / 3a', 12 \\
\hline 6 & 1a & {$\left[\operatorname{Ir}(\operatorname{cod})_{2}\right] \operatorname{OTf}(5)$} & $99 \%$ & $r a c$-BINAP & 2a, 85 / 2a', 3 / 3a', 8 \\
\hline $7^{e}$ & 1a & {$\left[\operatorname{Ir}(\operatorname{cod})_{2}\right] \mathrm{B} \operatorname{ArF}(5)$} & $74 \%$ & $r a c$-BINAP & $2 a, 71$ \\
\hline $8^{f}$ & $1 \mathrm{~b}$ & {$\left[\operatorname{Ir}(\operatorname{cod})_{2}\right] \mathrm{B} \operatorname{ArF}(5)$} & $99 \%$ & $r a c$-BINAP & $-g$ \\
\hline $9^{f, h}$ & 1c & {$\left[\operatorname{Ir}(\operatorname{cod})_{2}\right] \mathrm{BArF}(5)$} & $99 \%$ & $r a c$-BINAP & 5c, 42 \\
\hline $10^{i}$ & 1a & $\mathrm{RuH}_{2} \mathrm{CO}\left(\mathrm{PPh}_{3}\right)_{3}(5)$ & $99 \%$ & - & 2a', 7 / 3a', 61 \\
\hline
\end{tabular}

${ }^{a}$ Conditions: 1a was added to a solution of $[\mathrm{M}](\mathrm{x}$ mol\%) and $\mathrm{L}$ (x mol\%) in dioxane, unless otherwise noted, and the mixture was heated at $100{ }^{\circ} \mathrm{C}$ for 24 h. ${ }^{b}$ Isolated yields. ${ }^{c}$ Carried out in 1,2DCE $\left(100{ }^{\circ} \mathrm{C}\right.$, sealed tube). ${ }^{d}$ Carried out with $10 \mathrm{~mol} \%$ of $\mathrm{Ph}_{3} \mathrm{P} .{ }^{e}$ Carried out with NaOAc (20\%). ${ }^{f}$ Carried out at $120{ }^{\circ} \mathrm{C} .{ }^{g} \mathrm{~A}$ complex mixture of products is obtained. ${ }^{h}$ Reaction time: 6 days. ${ }^{i}$ Carried out in refluxing toluene. $\mathrm{d}^{\mathrm{F}}$ ppe: $\left(\mathrm{C}_{6} \mathrm{~F}_{5}\right)_{3} \mathrm{P}\left(\mathrm{CH}_{2}\right)_{2} \mathrm{P}\left(\mathrm{C}_{6} \mathrm{~F}_{5}\right)_{3}$.

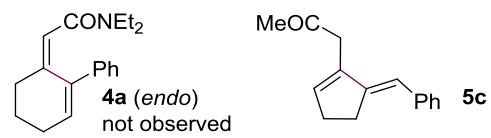

The counterion influences the outcome, with $\mathrm{BF}_{4}^{-}$or $\mathrm{TfO}^{-}$ leading to lower yields and the formation of small amounts of secondary products like 3a' (entries 5 and 6). Contrary to the $\mathrm{C}-\mathrm{H}$ alkenylation of indoles, which required the use of $\mathrm{NaOAc}(20 \mathrm{~mol} \%)$ to avoid partial isomerization of the product, ${ }^{5}$ this base is detrimental for the cyclization (entry 7). The nature of the directing group is critical, as substrates with an ethyl ester (1b) or a ketone (1c), instead of the amide, were unreactive at $100{ }^{\circ} \mathrm{C}$. Increasing the temperature up to $120^{\circ} \mathrm{C}$ led to some reactivity, albeit we observed mixtures of products (entry 8) or the formation of isomers like 5c (entry 9). Importantly, $\mathrm{Rh}$ and $\mathrm{Ru}$ catalysts previously found to be effective in intermolecular alkenylations, ${ }^{13}$ failed to give the desired products. We only observed some reactivity with
$\mathrm{RuH}_{2} \mathrm{CO}\left(\mathrm{PPh}_{3}\right)_{3}$, which produced mostly the isomeric product 3a' $(61 \%$, entry 10$) .{ }^{14}$ These results confirm that methods that work in intermolecular reactions do not necessarily translate to intramolecular cases.

The reaction is tolerant to both electron-donating and electron withdrawing substituents at the aryl group of the alkyne (Table 2 ), although, in the case of electron deficient substituents, obtaining good conversions required further heating. Nevertheless, the corresponding exo-dienyl cyclopentanes (2b-2f) were isolated with moderate to excellent yields and complete selectivities. Importantly, the reaction tolerates a one-carbon elongation of the tether, and the cyclohexane products $(\mathbf{2 g}-\mathbf{2 h})$ were obtained in excellent yields, even under relatively mild temperatures $\left(80^{\circ} \mathrm{C}\right)$. Finally, substrates with aryl linkers do also react to provide chromane derivatives like $\mathbf{2} \mathbf{i}$ in excellent yield (Table 2). ${ }^{15}$

Table 2. Intramolecular hydroalkenylation of alkynes ${ }^{a}$

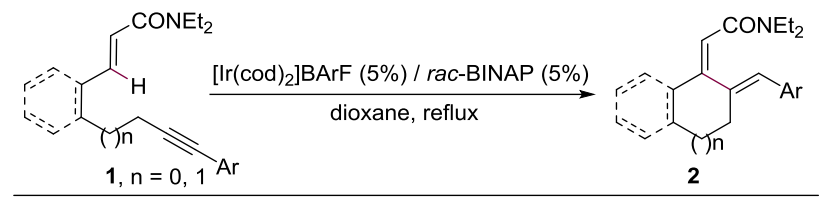

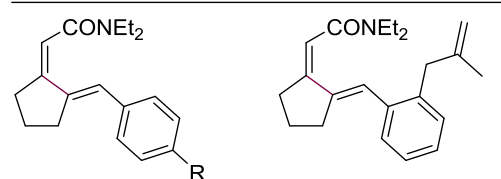

2a, $\mathrm{R}=\mathrm{H}, 92 \%$ yield 2b, $R=M e O, 98 \%$ yield 2c, $86 \%$ yield

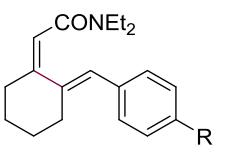

2g, $\mathrm{R}=\mathrm{H}, 92 \%$ yield $^{c}$ 2h, R $=\mathrm{CF}_{3}, 89 \%$ yield $^{c}$

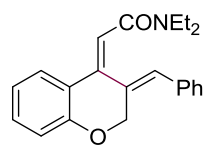

$2 \mathbf{i}, 85 \%$ yield

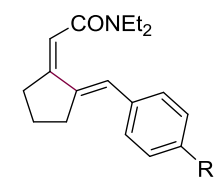
2d, $\mathrm{R}=\mathrm{CF}_{3}, 73 \%$ yield ${ }^{b}$ 2e, $\mathrm{R}=\mathrm{NO}_{2}, 54 \%$ yield $^{b}$ 2f, $\mathrm{R}=\mathrm{COMe}, 80 \%$ yield

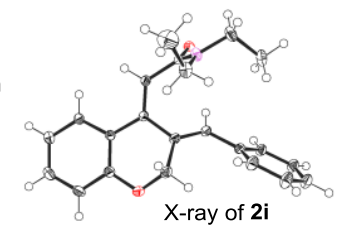

${ }^{a}$ Conditions: 1 was added to a solution of $\left[\operatorname{Ir}(\operatorname{cod})_{2}\right] \mathrm{BArF}(5 \%)$ and rac-BINAP (5\%) in dioxane and the mixture was refluxed for $19 \mathrm{~h}$. Isolated yields. ${ }^{b}$ Carried out at $120{ }^{\circ} \mathrm{C}$ (sealed tube). ${ }^{c}$ Carried out at $80^{\circ} \mathrm{C}$.

The presence of the exocyclic diene in the reaction products (2) suggested the possibility of further synthetic elaboration. Despite the diene is not electronically well posed to react with electron deficient alkenes, we observed that heating of $\mathbf{2 a}$ with $\mathrm{N}$-phenyl maleimide (4 equiv.) in dioxane at $140{ }^{\circ} \mathrm{C}$, provides the endo-cycloadduct 6 aa in $90 \%$ yield. ${ }^{12}$ Remarkably, both reactions, the cycloisomerization and the cycloaddition, can be carried out in the same pot. Therefore, direct heating of 1a with $\left[\operatorname{Ir}(\operatorname{cod})_{2}\right] \mathrm{BArF} / \mathrm{rac}$-BINAP in presence of $N$-phenyl maleimide (4 equiv) in dioxane at $140{ }^{\circ} \mathrm{C}$, for $24 \mathrm{~h}$, produces the tricyclic adduct 6 aa in $92 \%$ isolated yield (Scheme 2). Similarly, using methyl acrylate as reaction partner, we observed the product $\mathbf{6 a b}$ in $80 \%$ yield and 9:1 regioselectivity (major isomer shown, Scheme 2). It is important to remark the total chemoselectivity of the cycloisomerization in presence of excess of an externally added alkene, as this could also participate in competing intermolecular hydrocarbonations. Overall, the method provides a straightforward protocol to generate stereochemically rich polycarbocyclic products from simple acyclic starting materials, with full atom-economy. ${ }^{16}$ 


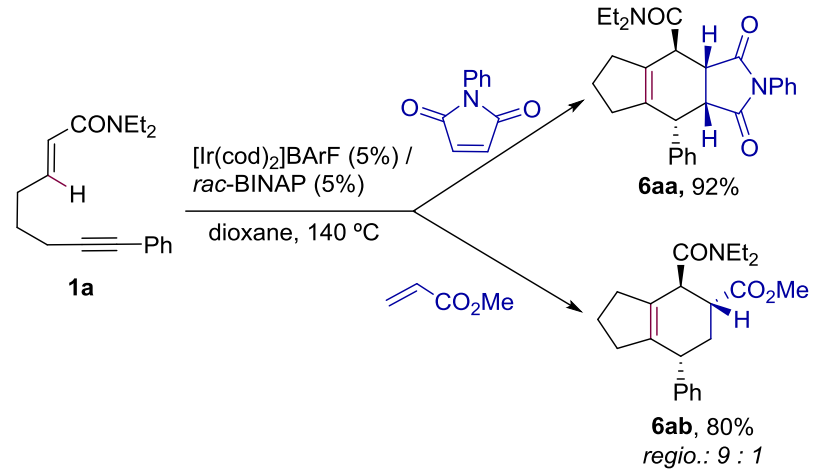

Scheme 2. Tandem, one-pot $\operatorname{Ir}(\mathrm{I})$-catalyzed C-H hydrocarbonation / Diels-Alder

We also analyzed related reactions involving the activation of aromatic and heteroaromatic $\mathrm{C}\left(\mathrm{sp}^{2}\right)-\mathrm{H}$ bonds. Importantly, the aryl carboxamide 7a undergoes a very efficient reaction to give the chromane derivative 8a (88\% yield, Table 3, entry 1$)$. Similarly to the olefinic series, the presence of electronwithdrawing groups at the aryl substituent of the alkyne somehow reduces the efficiency of the process $(\mathbf{8 b}, 48 \%$ yield, entry 2). Aliphatic substituents at the alkyne terminal position (e.g. methyl) are well tolerated, so that cyclization products like 8c could be obtained in 78\% yield (entry 3). Notably, the reaction was also effective in substrates with longer tethers like 7d, with the benzoxepine derivative $\mathbf{8 d}$ being obtained in $68 \%$ yield (entry 4). Interestingly, precursors with shorter tethers such as $\mathbf{7 e}$ led to an alternative endo-cyclization product (9e) albeit in low yield (entry 5). ${ }^{17}$

Table 3. Alkenylation of (hetero)aromatic systems ${ }^{a}$

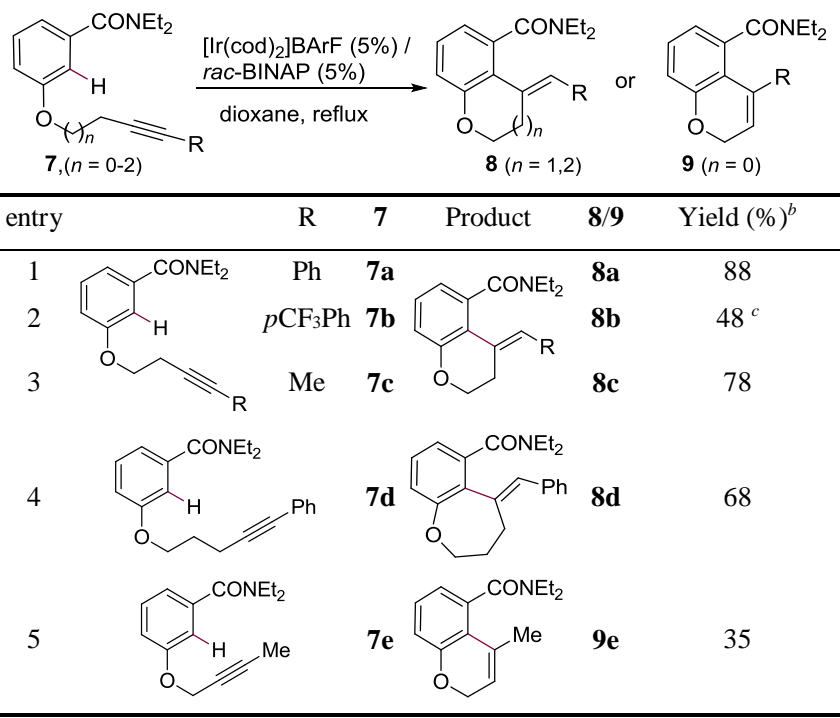

${ }^{a}$ Conditions: 7 was added to a solution of $\left[\operatorname{Ir}(\operatorname{cod})_{2}\right] \mathrm{B} \operatorname{ArF}(5 \%)$ and $r a c$-BINAP (5\%) in dioxane, and the mixture was heated under reflux for 24 h. ${ }^{b}$ Isolated yields. ${ }^{c}$ Carried out at $80{ }^{\circ} \mathrm{C}$ ( $73 \%$ conversion).

Importantly, the intramolecular hydrocarbonation of alkynes can also be efficiently accomplished in heteroaromatic systems, such as pyrroles. Thus, tetrahydroindolizine product $\mathbf{8 f}$ and $\mathbf{8 g}$ were efficiently obtained from the corresponding pyrrol-tethered alkynyl precursors upon heating at $80{ }^{\circ} \mathrm{C}$ in presence of $\left[\operatorname{Ir}(\operatorname{cod})_{2}\right] \mathrm{BArF} / \mathrm{rac}$-BINAP (Figure 1). The reactions also gave small amounts of isomeric dihydroindolizines. ${ }^{18}$ Gratifyingly, seven- and even eight-membered pyrrol-fused systems $\mathbf{8 h}$ and $\mathbf{8 i}$ could also be assembled in good yields and complete selectivity. Thus, the methodology provides a simple, efficient and atom-economical approach to challenging heteroaromatic systems bearing fused medium-sized carbocycles, structures that are difficult to assemble through alternative methodologies.

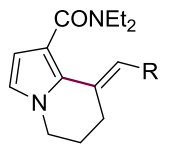

8f, $\mathrm{R}=\mathrm{Ph}, 79 \%$ $8 \mathrm{~g}, \mathrm{R}=p \mathrm{CF}_{3} \mathrm{Ph}, 69 \%$

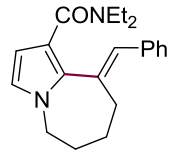

8h, $96 \%$

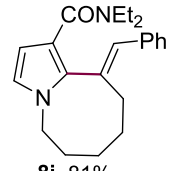

$8 \mathbf{8 i}, 81 \%$

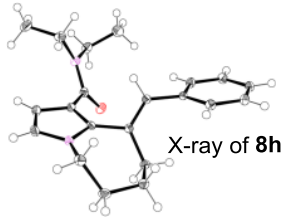

Figure 1. Intramolecular hydrocarbonation of alkynes with pyrroles; X-ray of $\mathbf{8 h}$.

Mechanistically informative, treatment of deuterated precursor $\boldsymbol{d}$-1i under standard reaction conditions provided the expected cycle with complete and exclusive incorporation of deuterium at the vinylic position, confirming that an $\operatorname{Ir}(\mathrm{III})$-hydride intermediate of type $\mathbf{I}$ is involved (Scheme 3). ${ }^{19}$ However, the evolution of this intermediate to the product could either occur via a hydroiridation or a carboiridation process.

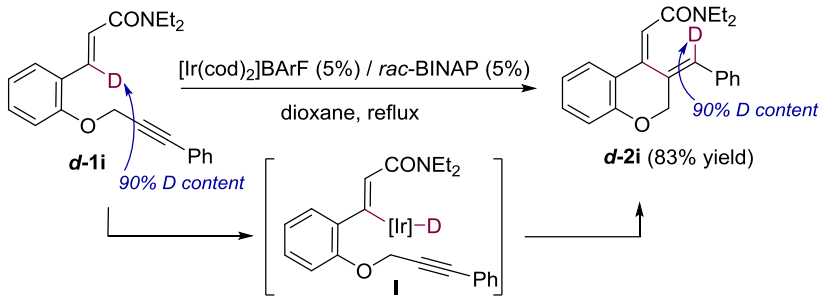

Scheme 3. Mechanistic probe.

To shed light into these competitive pathways, we performed a DFT theoretical analysis using the model substrate 1a', and dppe as ligand. ${ }^{12,20}$ As can be seen in the Figure 2, the $\mathrm{C}-\mathrm{H}$ activation step exhibits the highest energy barrier of the process (TS1, $\left.21.9 \mathrm{kcal} \cdot \mathrm{mol}^{-1}\right){ }^{21}$ and leads to intermediate Int-1, which might conformationally relax to the most stable $\operatorname{Ir}(\mathrm{III})$ intermediates Int-1b and Int-1a, respectively. From Int-1b, a pathway based on an hydroiridation of the alkyne followed by a subsequent $\mathrm{C}-\mathrm{C}$ reductive elimination seems very plausible, with calculated energy barriers of 9.0 and $12.1 \mathrm{kcal} \cdot \mathrm{mol}^{-1}$, respectively (red pathway). Alternatively, from the more stable iridium-hydride isomer of type Int-1a $(\Delta \Delta \mathrm{G}=10.8$ $\mathrm{Kcal} \cdot \mathrm{mol}^{-1}$ ), which bears the carbonyl and the hydride in trans disposition, a carboiridation / $\mathrm{C}-\mathrm{H}$ reductive elimination sequence can also be proposed. While the carbometalation presents an energy barrier of $20.0 \mathrm{kcal} \cdot \mathrm{mol}^{-1}$, close to that of the previous iridium oxidative addition step, the final $\mathrm{C}-\mathrm{H}$ reductive elimination has the lowest barrier of the catalytic cycle, $7.6 \mathrm{kcal} \cdot \mathrm{mol}^{-1}$, and both steps proceed through energetic maxima significantly below to that of TS1 $\left(16.9 \mathrm{kcal} \cdot \mathrm{mol}^{-1}\right.$ for TS2a and 0.4 for TS3a, blue pathway). Therefore, the TOFdetermining transition state of the process is that associated to the initial oxidative addition (TS1), ${ }^{22}$ and both the hydrometalation and the carbometalation pathways are viable. However, the $\mathrm{C}-\mathrm{H}$ reductive elimination presents a lower energetic barrier than the $\mathrm{C}-\mathrm{C}$ forming process. This mechanistic sce- 
nario is compatible with a H/D KIE value of $\sim 2$, which was measured for the cyclizations of model substrates $\mathbf{1 i}$ and $d-\mathbf{1 i} .^{12}$ Overall, these results suggest a different energetic profile than that previously proposed for intramolecular carboxamideassisted hydrocarbonation of alkenes, ${ }^{8,9}$ wherein the carbomet- alation and $\mathrm{C}-\mathrm{C}$ reductive elimination steps have energy barriers larger than that of the $\mathrm{C}-\mathrm{H}$ insertion. In the current case, the fact that there is a migratory insertion of an alkyne instead of an alkene, and that the reductive elimination involves a $\mathrm{sp}^{2}$ rather than $\mathrm{a} \mathrm{sp}^{3}$-carbon, might account for the difference.
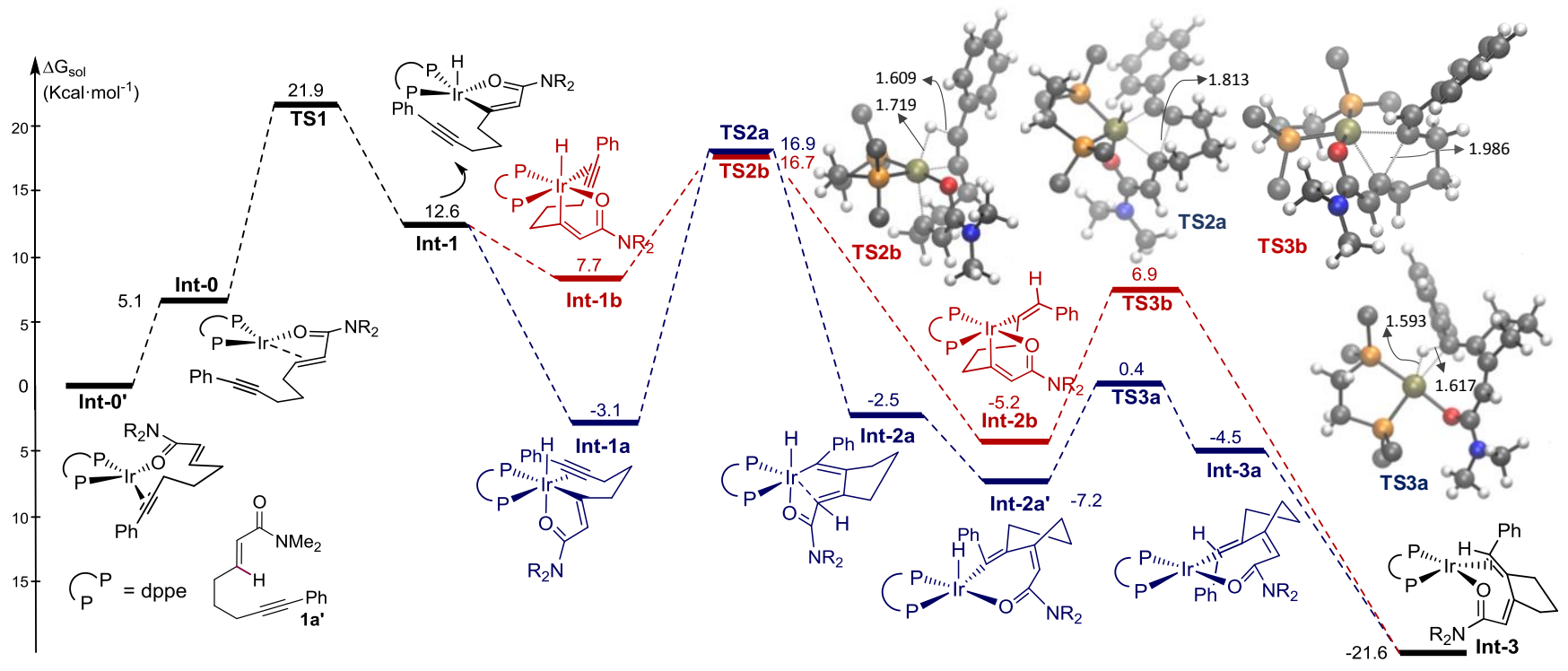

Figure 2. Energy profile $\Delta \mathrm{G}^{\text {solv }}\left(\mathrm{kcal} \cdot \mathrm{mol}^{-1}\right)$ for the hydrocarbonation of 1a' $(\mathrm{R}=\mathrm{Me}){ }^{18}$ Phenyl rings of dppe are omitted for clarity. Key bond distances in $\AA$

In summary, we have developed the first examples of iridiumcatalyzed cycloisomerizations of enynes involving a $\mathrm{C}-\mathrm{H}$ activation process. The reactions provide cyclic systems bearing an exo-dienyl moiety with defined stereochemistry. The method, which relies on a carboxamide-assisted $\mathrm{C}-\mathrm{H}$ activation, is also suitable for substrates with aromatic and heteroaromatic $\mathrm{C}-\mathrm{H}$ bonds. Importantly, the reaction allows the construction of five to eight-membered rings, and can be coupled to $[4+2]$ cycloadditions in an one-pot process, thus allowing a straightforward, stereoselective entry to relatively complex polycyclic systems. Finally, DFT calculations confirmed the initial oxidative addition as rate determining step, and that both, the carbometalation and hydrometalation paths, are energetically feasible, albeit the former presents an easier $\mathrm{C}-\mathrm{H}$ reductive elimination.

\section{AUTHOR INFORMATION}

\section{Corresponding Author}

* E-mail: Prof. J. L. Mascareñas. joseluis.mascarenas@ usc.es, Dr. F. Lopéz.: fernando.lopez@ csic.es

\section{Notes}

The authors declare no competing financial interest.

\section{Author Contributions}

$\S$ These authors contributed equally.

\section{ASSOCIATED CONTENT}

Supporting Information. Full experimental procedures, optimization of the catalyst and characterization of all new compounds, including ${ }^{1} \mathrm{H}-,{ }^{13} \mathrm{C}$-NMR spectra.This material is available free of charge via the Internet at http://pubs.acs.org.

\section{ACKNOWLEDGMENT}

This work received financial support from the spanish MINECO (SAF2016-76689-R, CTQ2016-77047-P, CTQ2017-84767-P, FPI fellowship to D.F.F.), the Xunta de Galicia (ED431C 2017/19, 2015-CP082, Centro Singular de Investigación de Galicia accreditation 2016-2019 ED431G/09 and predoctoral fellowship to M.C.), the ERDF, ERC (Adv. Grant No. 340055) and the OrfeoCinqa network (CTQ2016-81797-REDC). Dr. Rebeca GarcíaFandiño is acknowledged for helpful suggestions on DFT studies.

\section{REFERENCES}

(1) (a) $\mathrm{C}-\mathrm{H}$ Bond Activation and Catalytic Functionalization I, Dixneuf, P. H., Doucet, H. Eds.; Springer, Heidelberg, 2016; pp 1260. (b) Chen, Z.; Wang, B.; Zhang, J.; Yu, W.; Liu, Z.; Zhang, Y. Transition Metal-Catalyzed C-H Bond Functionalizations by the Use of Diverse Directing Groups. Org. Chem. Front. 2015, 2, 1107-1295. (c) Wencel-Delord, J.; Glorius, F. C-H Bond Activation Enables the Rapid Construction and Late-Stage Diversification of Functional Molecules. Nat. Chem. 2013, 5, 369-375. (d) C-H Activation, Yu, J.Q., Ackermann, L., Shi, Z. Eds.; Springer, Heidelberg, 2010; pp 1378. (e) Gulías, M.; Mascareñas, J. L. Metal-Catalyzed Annulations through Activation and Cleavage of $\mathrm{C}-\mathrm{H}$ Bonds. Angew. Chem. Int. Ed. 2016, 55, 11000-11019. (f) Trost, B. M.; Krische, M. J. Transition Metal Catalyzed Cycloisomerizations. Synlett 1998, 1-16.

(2) For selected recent reviews, see: (a) Li, B.-J.; Shi, Z.-J. in Homogeneous Catalysis for Unreactive Bond Activation, Shi, Z.-J., Ed.; John Wiley \& Sons, New Jersey, 2015; pp 472-474. (b) Colby, D. A.; Bergman, R. G.; Ellman, J. A. Rhodium-Catalyzed C-C Bond Formation via Heteroatom-Directed $\mathrm{C}-\mathrm{H}$ Bond Activation. Chem. Rev. 2010, 110, 624-655. (c) Nakao, Y. Hydroarylation of Alkynes Catalyzed by Nickel. Chem. Rec. 2011, 11, 242-251. (d) Pan, S.; Shibata, $\mathrm{T}$. Recent Advances in Iridium-Catalyzed Alkylation of $\mathrm{C}-\mathrm{H}$ and $\mathrm{N}-$ H Bonds. ACS Catal. 2013, 3, 704-712. (e) De Sarkar, S.; Liu, W. P.; Kozhushkov, S. I.; Ackermann, L. Weakly Coordinating Directing Groups for Ruthenium(II)-Catalyzed C-H Activation. Adv. Synth. Catal. 2014, 356, 1461-1479. (f) Boyarskiy, V. P.; Ryabukhin, D. S.; Bokach, N. A.; Vasilyev, A. V. Alkenylation of Arenes and Heteroarenes with Alkynes. Chem. Rev. 2016, 116, 5894-5986. (g) Dong, Z.; Ren, Z.; Thompson, S. J.; Xu, Y.; Dong, G. Transition-Metal- 
Catalyzed C-H Alkylation Using Alkenes, Chem. Rev. 2017, 117, 9333-9403.

(3) (a) Nishinaka, Y.; Satoh, T.; Miura, M.; Morisaka, H.; Nomura, M.; Matsui, H.; Yamaguchi, C. Iridium-Catalyzed Reaction of 1Naphthols, $N$-(1-Naphthyl)benzenesulfonamides, and Salicylaldehyde with Internal Alkynes. Bull. Chem. Soc. Jpn. 2001, 74, 1727-1735. (b) Tsuchikama, K.; Kasagawa, M.; Hashimoto, Y.-K.; Endo, K.; Shibata, T. Cationic Iridium-BINAP Complex-Catalyzed Addition of Aryl Ketones to Alkynes and Alkenes via Directed C-H Bond Cleavage. J. Organomet. Chem. 2008, 693, 3939-3942. (c) Sevov, C. S.; Hartwig, J. F. Iridium-Catalyzed Oxidative Olefination of Furans with Unactivated Alkenes. J. Am. Chem. Soc. 2014, 136, 10625-10631. (d) Nagamoto, M.; Fukuda, J.; Hatano, M.; Yorimitsu, H.; Nishimura, T. Hydroxoiridium-Catalyzed Hydroarylation of Alkynes and Bicycloalkenes with $\mathrm{N}$-Sulfonylbenzamides. Org. Lett. 2017, 19, 5952-5955. For an example with allenes, see: (e) Zhang, Y. J.; Skucas, E.; Krische, M. J. Direct Prenylation of Aromatic and $\alpha, \beta$-Unsaturated Carboxamides via Iridium-Catalyzed $\mathrm{C}-\mathrm{H}$ Oxidative Addition-Allene Insertion. Org. Lett. 2009, 11, 4248-4250.

(4) (a) Yotphan, S.; Bergman, R. G.; Ellman, J. A. The Stereoselective Formation of Bicyclic Enamines with Bridgehead Unsaturation via Tandem $\mathrm{C}-\mathrm{H}$ Bond Activation/Alkenylation/Electrocyclization. $J$. Am. Chem. Soc. 2008, 130, 2452-2453. (b) Matsushima, Y.; Phillips, E. M.; Bergman, R. G.; Ellman, J. A. Rhodium(I)-Catalyzed Cycloisomerization of 1,6-Enynes. Synlett 2015, 26, 1533-1536.

(5) Shibata, T.; Baba, T.; Takano, H.; Kanyiva, K. S. Intramolecular $\mathrm{C}-\mathrm{H}$ Alkenylation of $N$-Alkynylindoles: Exo and Endo Selective Cyclization According to the Choice of Metal Catalyst. Adv. Synth. Catal. 2017, 359, 1849-1853.

(6) An alternative to these processes consists of the use high valent metal catalysts (e.g $\left.\mathrm{Rh}^{\mathrm{III}}, \mathrm{Ir}^{\mathrm{III}}\right)$, albeit they are mechanistically different. Still, intramolecular hydrocarbonations of alkynes using $\mathrm{C}\left(\mathrm{sp}^{2}\right)-\mathrm{H}$ bonds are limited to a couple of Rh-catalyzed processes: (a) Shibata, T.; Takayasu, S.; Yuzawa, S.; Otani, T. Rh(III)-Catalyzed C$\mathrm{H}$ Bond Activation along with "Rollover" for the Synthesis of 4Azafluorenes. Org. Lett. 2012, 14, 5106-5109. (b) Zhang, X.; Li, Y.; Shi, H.; Zhang, L.; Zhang, S.; Xu, X.; Liu, Q. Rhodium(III)Catalyzed Intramolecular Amidoarylation and Hydroarylation of Alkyne via C-H Activation: Switchable Synthesis of 3,4-Fused Tricyclic Indoles and Chromans. Chem. Commun. 2014, 50, 7306-7309.

(7) (a) Huang, G.; Liu, P. Mechanism and Origins of LigandControlled Linear Versus Branched Selectivity of Iridium-Catalyzed Hydroarylation of Alkenes. ACS Catal. 2016, 6, 809-820. (b) Zhang, M.; Huang, G. Mechanism of Iridium-Catalysed Branched-Selective Hydroarylation of Vinyl Ethers: a Computational Study. Dalton Trans. 2016, 45, 3552-3557. (c) Hatano, M.; Ebe, Y.; Nishimura, T.; Yorimitsu, H. Asymmetric Alkylation of $N$-Sulfonylbenzamides with Vinyl Ethers via C-H Bond Activation Catalyzed by Hydroxoiridium/Chiral Diene Complexes. J. Am. Chem. Soc. 2016, 138, 40104013. (d) Xing, D.; Dong, G. Branched-Selective Intermolecular Ketone $\alpha$-Alkylation with Unactivated Alkenes via an Enamide Directing Strategy, J. Am. Chem. Soc. 2017, 139, 13664-13667. (e) Li, X.; Wu, H.; Lang, Y.; Huang, G. Mechanism, Selectivity, and Reactivity of Iridium- and Rhodium-Catalyzed Intermolecular Ketone $\alpha$ Alkylation with Unactivated Olefins Via an Enamide Directing Strategy. Catal. Sci. Technol. 2018, 8, 2417-2426. (f) Zhang, M.; Hu, L.; Lang, Y.; Cao, Y.; Huang, G. Mechanism and Origins of Regio- and Enantioselectivities of Iridium-Catalyzed Hydroarylation of Alkenyl Ethers. J. Org. Chem. 2018, 83, 2937-2947.

(8) For intramolecular hydrocarbonation of alkenes, see: Fernández, D. F.; Gulías, M.; Mascareñas, J. L.; López, F. Iridium(I)Catalyzed Intramolecular Hydrocarbonation of Alkenes: Efficient Access to Cyclic Systems Bearing Quaternary Stereocenters. Angew. Chem. Int. Ed. 2017, 56, 9541-9545.

(9) Lang, Y.; Zhang, M.; Cao, Y.; Huang, G. Mechanism and Origins of the Directing Group-Controlled Endo- Versus Exo-Selectivity of Iridium-Catalysed Intramolecular Hydroalkenylation of 1,1Disubstituted Alkenes. Chem. Commun. 2018, 54, 2678-2681.

(10) Intramolecular hydrocarbonations of $\mathrm{C}-\mathrm{C}$ unsaturated bonds using olefinic $\mathrm{C}\left(\mathrm{sp}^{2}\right)-\mathrm{H}$ bonds are very scarce. See ref 4 for examples with alkynes. For alkenes, see: (a) Fujii, N.; Kakiuchi, F.; Chatani, N.; Murai, S. Transition Metal-Catalyzed Intramolecular C-H/Olefin Coupling. Chem. Lett. 1996, 25, 939-940. (b) Tsai, A. S.; Bergman, R. G.; Ellman, J. A. Asymmetric Synthesis of (-)-Incarvillateine Employing an Intramolecular Alkylation via Rh-Catalyzed Olefinic C-H Bond Activation. J. Am. Chem. Soc. 2008, 130, 6316-6317. (c) Aissa, C.; Fürstner, A. A Rhodium-Catalyzed C-H Activation/Cycloisomerization Tandem. J. Am. Chem. Soc. 2007, 129, 14836-14837. (d) Aissa, C.; Ho, K. Y. T.; Tetlow, D. J.; Pin-Nó, M. Diastereoselective Carbocyclization of 1,6- Heptadienes Triggered by Rhodium-Catalyzed Activation of an Olefinic C-H Bond. Angew. Chem. Int. Ed. 2014, 53, 4209-4212.

(11) For the use of $d^{\mathrm{F}}$ ppe in Ir-catalyzed reactions, see: Crisenza, G. E. M.; McCreanor, N. G.; Bower, J. F. Iridium-Catalyzed Hydroarylation of Monosubstituted Alkenes via a Cooperative Destabilization Strategy. J. Am. Chem. Soc. 2014, 136, 10258.

(12) See the Supporting Information for further details.

(13) For Ru, see: (a) Kakiuchi, F.; Uetsuhara, T.; Tanaka, Y.; Chatani, N.; Murai, S. Ruthenium-Catalyzed Addition of Olefinic C$\mathrm{H}$ Bonds in Conjugate Enones to Acetylenes to Give Conjugate Dienones. J. Mol. Catal. A: Chem. 2002, 511-514. (b) Neisius, N. M.; Plietker, B. The Ruthenium-Catalyzed Hydrovinylation of Internal Alkynes by Acrylates: An Atom Economic Approach to Highly Substituted 1,3- Dienes. Angew. Chem. Int. Ed. 2009, 48, 5752-5755. (c) Nishida, M.; Adachi, N.; Onozuka, K.; Matsumura, H.; Mori, M. Intramolecular Cyclizations of Enynes Using $\mathrm{RuClH}(\mathrm{CO})\left(\mathrm{PPh}_{3}\right)_{3} . J$. Org. Chem. 1998, 63, 9158-9159. For Rh, see: (d) Colby, D. A.; Bergman, R. G.; Ellman, J. A. Stereoselective Alkylation of $\alpha, \beta-$ Unsaturated Imines via $\mathrm{C}-\mathrm{H}$ Bond Activation. J. Am. Chem. Soc. 2006, 128, 5604- 605. (e) Shibata, Y.; Otake, Y.; Hirano, M.; Tanaka, K. Amide-Directed Alkenylation of $\mathrm{sp}^{2} \mathrm{C}-\mathrm{H}$ Bonds Catalyzed by a Cationic Rh(I)/BIPHEP Complex Under Mild Conditions: Dramatic Rate Acceleration by a 1-Pyrrolidinecarbonyl Group. Org. Lett. 2009, 11, 689-692.

(14) (a) Control experiments suggest that product 3a' can be obtained from 2a' under reaction conditions. (b) With this Ru catalyst, 2a was never detected, even at lower temperatures or shorter reaction times, suggesting that it proceeds through a different mechanism. See Ref. 13c.

(15) Traces of isomers of type 2' could only be detected in the reaction crudes of $\mathbf{1 e}$ and $\mathbf{1 f}$.

(16) Wender, P. A.; Gamber, G. G.; Scanio, M. J. C. Serial [5+2]/[4+2] Cycloadditions: Facile, Preparative, Multi-Component Syntheses of Polycyclic Compounds from Simple, Readily Available Starting Materials. Angew. Chem. Int. Ed. 2001, 40, 3895-3897.

(17) Probably, an exo migratory insertion is highly impeded due to conformation constrains imposed by the shorter tether (vide infra).

(18) Control experiments suggest that the isomeric sideproducts are obtained from $\mathbf{8 f}$ and $\mathbf{8 g}$, under reaction conditions. This isomerization is also observed under soft acidic conditions $\left(\mathrm{CHCl}_{3}\right.$ that contains traces of hydrochloric acid). See the Supp. Info.

(19) An alternative mechanisms based on hydrometalations (e.g. ref $13 \mathrm{c}$ ) or through oxidative metalacycles are very unlikely since would provide isomers of type $\mathbf{2}$ '.

(20) Optimization of geometries was carried out at the M06 / 6$31 \mathrm{G}(\mathrm{d}, \mathrm{p})$ level (SDD for Ir), and single point calculations at M06 / 6$311++\mathrm{G}(\mathrm{d}, \mathrm{p})$;SDD for Ir. Reported values correspond to solvationcorrected relative free-energies obtained at this level (solvent $=$ dioxane). See the Supp. Info.

(21) The C-H activation can also occur from Int-0', wherein the alkyne is coordinated to the Ir, with an almost identical barrier. See the Supp. Info.

(22) (a) Kozuch, S. Steady State Kinetics of Any Catalytic Network: Graph Theory, the Energy Span Model, the Analogy between Catalysis and Electrical Circuits, and the Meaning of "Mechanism", ACS Catal. 2015, 5, 5242-5255. (b) Kozuch, S.; Shaik, S. How to Conceptualize Catalytic Cycles? The Energetic Span Model, Acc. Chem. Res. 2011, 44, 101-110. 
Insert Table of Contents artwork here

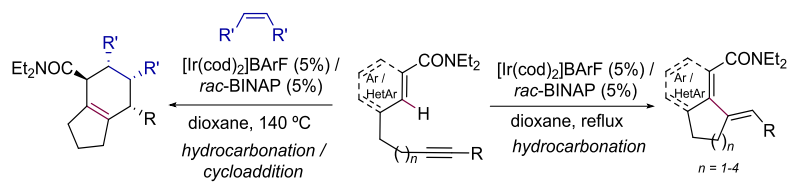

